\title{
$\beta$-Endorphin May Be a Mediator of Apnea Induced by the Laryngeal Chemoreflex in Piglets
}

\author{
HANNE STORM, I.ALRITZ STOLTENBERG, STEPHANIY ØYASAETER, OLA D. SAUGSTAD, \\ TORI.EIV O. ROGNUM, AND KARL L. REICHEIT \\ Department of Pediatric Research IH.S., L.S., S.O., O.D.S., K.L.R.J, Institute of Forensic Medicine \\ IT.O.R.J and the' Institute for Surgical Research. National Hospital, Oslo, Norway
}

\begin{abstract}
To determine whether $\beta$-endorphin is involved in the laryngeal chemoreflex, we initially injected $0.01 .1 \mathrm{mg}$ of $\beta$-endorphin into the cisterna magna (i.c.m.) and registered the respiratory and cardiovascular patterns in $5-10$-d-old piglets. From 0.1 to $1 \mathrm{mg}$ of $\beta$-endorphin i.c.m. induced a decrease in the minute volume, heart rate, and blood pressure within $15 \mathrm{~min}$. Within the next 30 min respiratory pauses accompanied by hlood pressure increases and reductions in heart rate developed, similar to the respiratory and cardiovascular pattern of the induced laryngeal chemoreflex. Based on these initial data, we decided to induce a laryngeal chemoreffex in piglets pretreated with $0.1 \mathrm{mg}$ of $\beta$-endorphin i.c.m $(n=6), 0.2 \mathrm{mg}$ of $\beta$-endorphin i.c.m. $(n-6), 0.1 \mathrm{mg}$ of $\beta$-endorphin i.c.m. and $100 \mu \mathrm{g} / \mathrm{kg}$ naloxone i.v. $(n=6), \mathrm{J} 00$ $\mu \mathrm{g} / \mathrm{kg}$ naloxone i.v. $(n=6)$, or water i.c.m. $(n=6)$. Because elevated levels of hypoxanthine in the vitreous humor may indicate hypoxia before death, we therefore measured the postmortem hypoxanthine levels in the vitreous humor. The laryngeal
\end{abstract}

ABSTRACT
Infants with apnea and increased levels of $\beta$-endorphin immunoreactivity in the CSF have been successfully treated with the $\mu$-receptor antagonist naloxone i.v. (1-3). $\beta$-Endorphin is a $\mu$-agonist, and may depress the respiratory rate, tidal volume, and heart rate when injected i.c.m. (4). Furthermore, infants with apnea caused by gastroesophageal reflux have increased levels of $\beta$-endorphin immunoreactivity in plasma (5). After correction of gastrocsophageal refluxes in infants with acute life threatening episodes, the plasma $\beta$-endorphin levels decreased (6).

The gastroesophageal reflux may stimulate the laryngeal chemoreflex and result in apnea, decreased heart rate, and increased blood pressure (7). In dogs the duration of the laryngeal chemoreflex-induced apnea and the decrease in the heart rate were reduced after treatment with naloxone (8). When this reflex was induced in piglets, $\beta$-endorphin was released into the CSF, and the levels of $\beta$-endorphin immuno-

Received September 15, 1994; accepted March 16, 1995

Correspondence: Hanne Storm, M.D., Paedatric Research, National Hospital. Pilestredet 32, $\mathrm{V}-(1)(027$, Oslo, Nonway.

Supported by the Research Council of Norway. and the Norwegian SIDS Society. chemoreflex-induced apnea was shortenec in the piglet group pretreated with water i.c.m and naloxone i.v. $(p<0.01)$ and in the piglet group pretreated with $0.1 \mathrm{mg}$ of $\beta$-endorphin i.c.m and naloxone i.v. $(p<0.05)$, but not significantly prolonged in the piglet groups pretreated with 0.1 or $0.2 \mathrm{mg}$ of $\beta$-endorphin i.c.m. when compared with the piglets pretreated with water i.c.m. The hypoxanthine levels in the vitreous humor were found increased after death only in piglets pretreated with $0.2 \mathrm{mg}$ of $\beta$-endorphin i.c.m. before the laryngeal chemoreflex was induced $(p<0.05)$. We conclude that $\beta$-endorphin is probably a mediator of apnea induced by the laryngeal chemoreflex in piglets. (Pediatr Res 38: 205-210, 1995)

\author{
Abbreviations \\ i.c.m, in cisterna magna \\ CSF, cerebrospinal fluid
}

reactivity in the CSF correlated with the duration of the apnea (9). Interestingly, hypoxia does not increase the $\beta$-endorphin immunoreactivity levels in the CSF $(10,11)$.

To investigate the possibility that $\beta$-endorphin is involved in the laryngeal chemoreflex-induced apnea, we injected different doses of $\beta$-endorphin i.c.m. in 5-10-d-old piglets and followed their respiratory and cardiovascular patterns. From 0.1 to $1 \mathrm{mg}$ of $\beta$-endorphin i.c.m. induced respiratory pauses accompanied by blood pressure increases and reductions in heart rate within $30 \mathrm{~min}$, similar to the respiratory and cardiovascular pattern seen during the laryngeal chemoreflex.

Based on these initial experiments, we found that $0.1 \mathrm{mg}$ of $\beta$-endorphin i.c.m. was the lowest effective dose inducing respiratory pauses accompanied by blood pressure increases and reductions in heart rate. We therefore studied the laryngeal chemoreflex in piglets pretreated with $0.1 \mathrm{mg}$ of $\beta$-endorphin i.c.m. $(n=6), 0.2 \mathrm{mg} \beta$-endorphin i.c.m. $(n=6), 0.1 \mathrm{mg}$ $\beta$-endorphin i.c.m. and $100 \mu \mathrm{g} / \mathrm{kg}$ naloxone i.v. $(n-6), 100$ $\mu \mathrm{g} / \mathrm{kg}$ naloxone i.v. $(n-6)$, or water i.c.m. $(n=6)$. Because elevated levels of hypoxanthine in vitreous humor may indicate hypoxia before death, we therefore measured the postmortem hypoxanthine levels in the vitreous humor (12). 


\section{METHODS}

Approval. The experimental protocol was approved by the hospital's ethical committee for animal studies.

Animals. Forty-nine piglets (5-10-d-old; median weight, 2.6 $\mathrm{kg}$; weight range, $1.3-3.9 \mathrm{~kg} ; 31$ males and 18 females) were delivered from a local farmer on the day of the experiments. They were premedicated with azaperone ( $4 \mathrm{mg} / \mathrm{kg}$ i.m.), cannulated in a peripheral ear vein, and given metomidate until adequate anesthesia was achieved (4-10 mg/kg i.v.). Additional metomidate $(4 \mathrm{mg} / \mathrm{kg})$ was given when necessary. After local lidocaine injection tracheotomy was performed with a 3.0-3.5-mm cuffed Sheridan endotracheal tube, depending on tracheal size. The tube was connected via a small humidifier (Portex Termovent 600) to a Servo 900 B ventilator (ElemaSchønander, Stockholm, Sweden). The pigs were mechanically ventilated throughout the operation at 40 breaths $/ \mathrm{min}$. Tidal volume was adjusted when necessary to maintain arterial $\mathrm{PCO}_{2}$ at $4.6-5.9 \mathrm{kPa}$. A small Foley urine catheter (Silastic Foley, $2.7 \mathrm{~mm} / 8 \mathrm{Ch} .3 \mathrm{~mL}$, Dow Corning SA, Valbonne, France) was inserted through the tracheostomy, directed rostral, and placed in the subglottal space. The piglets remained on the respirator for $60 \mathrm{~min}$ after surgery, after which at least $30 \mathrm{~min}$ of spontaneous respiration was necessary, to attain stable respiratory conditions. The respiratory rate, minute volume, and tidal volume were monitored continuously for the rest of the experiment with a Bear NVM-1 Neonatal Volume Monitor (Bear Medical Systems Inc., Riverside CA) and with a TOA EPR-131-A electronic polyrecorder (Semitronic A/S, Japan). The rectal temperature was monitored continuously and maintained at $38.0-39.5^{\circ} \mathrm{C}$ by means of a heating blanket and when necessary a heating lamp. A catheter was inserted into a superficial artery on the inside of the hind leg and connected to a strain gauge transducer, so that the mean arterial blood pressure could be recorded continuously by a Gould recorder 2600S (Gould Inc. Recording Systems, Cleveland, OH). The pulse was monitored continuously via skin electrodes. A urinary catheter was placed in the bladder through a midline suprapubic laparotomy. Through the ear vein a solution containing $0.7 \% \mathrm{NaCl}$ was administered at a rate of $10 \mathrm{~mL} / \mathrm{kg} / \mathrm{h}$. Blood glucose was measured with a reflectometer (Hypocount MX B, Boehringer, Mannheim, FGR). A lumbar puncture needle was inserted i.c.m., and about 6 droplets of CSF were withdrawn before $200 \mu \mathrm{L}$ of water or various concentrations of $\beta$-endorphin were injected. After this the respiratory and cardiovascular patterns were recorded and/or the laryngeal chemoreflex was induced.

In this study a period of apnea was defined as the respiratory response to insufflation of the larynx with ammonia-saturated air. Several small pieces of gauze soaked in $6 \mathrm{~mL}$ of ammonia (10.8 M, Prolabo ammonia solution, minimum 20\%, density 0.92 analytical reagent; Paris, France) were placed in a $50-\mathrm{mL}$ syringe, and $23 \mathrm{~mL}$ of ammonia-saturated air were injected. The piglets were killed with pentobarbital at the end of the trial.

Experimental protocol. As a pilot experiment $1 \mathrm{mg}(n=1)$, $0.5 \mathrm{mg}(n=1), 0.1 \mathrm{mg}(n=7)$, and $0.01 \mathrm{mg}(n=1)$ of $\beta$-endorphin or water $(n=2)$ were injected i.c.m., and the respiratory and cardiovascular patterns were recorded.

Based on these initial experiments, $0.1 \mathrm{mg}$ of $\beta$-endorphin i.c.m. was found to be the lowest dose inducing respiratory pauses accompanied by blood pressure increases and reductions in heart rate. We therefore decided to inject 0.1 or $0.2 \mathrm{mg}$ of $\beta$-endorphin i.c.m. before we induced the laryngeal chemoreflex. Piglets were randomized to laryngeal chemoreflexinduced apnea pretreated with water i.c.m. $(n=6)$, with 0.1 $\mathrm{mg}$ of $\beta$-endorphin i.c.m. $(n=6)$, with $0.2 \mathrm{mg}$ of $\beta$-endorphin i.c.m. $(n=6)$, with water i.c.m. and $100 \mu \mathrm{g}$ of naloxone $\mathrm{kg}^{-1}$ i.v. $(n=6)$, and with $0.1 \mathrm{mg}$ of $\beta$-endorphin i.c.m. and $100 \mu \mathrm{g}$ of naloxone $\mathrm{kg}^{-1}$ i.v. $(n=6)$. Only those piglets with arterial $\mathrm{O}_{2}$ tension $\left(\mathrm{PaO}_{2}\right)>9.0 \mathrm{kPa}, \mathrm{PaCO}_{2}<5.5 \mathrm{kPa}$, and base excess $>-6 \mathrm{mmol} / \mathrm{L}$ were randomized into the groups.

Piglets with $\mathrm{PaO}_{2}<9.0 \mathrm{kPa}, \mathrm{PaCO}_{2}>5.5 \mathrm{kPa}$, or base excess $>-6 \mathrm{mmol} / \mathrm{L}(n=7)$ were given water i.c.m. and one period of apnea. These piglets were used together with the randomized piglets which were pretreated with water i.c.m. before the laryngeal chemoreflex $(n=6)$, for relating increase in blood pressure, decrease in heart rate, and apnea duration. In these piglets $(n=13)$ we also compared the blood gases and the respiratory minute volume before and after each apnea.

Blood samples. Arterial blood samples were taken throughout the trial and before and 5 min after each period of apnea. Temperature-corrected blood gases were measured with an AVL 945 automatic blood gas system (AVL Biomedical Instruments, Schaffhausen, Switzerland). $\mathrm{Hb}$ was measured with a CO-oximeter 482 (Bergman Instrumentering A/S, Lexington, MA), and hematocrit with a Hematastat (model TM C-70, Separation Technology Inc., Salt Lake City, UT). The withdrawn blood was replaced with an equal volume of sterile $\mathrm{NaCl}$ $(0.9 \%)$, and the catheter was flushed with heparinized saline (4 $\mathrm{U} / \mathrm{mL})$.

Sampling of vitreous humor. The vitreous humor was collected from the piglets immediately (within $5 \mathrm{~min}$ ) after death. The conjunctiva was dissected free from the sclera. Vitreous humor was sampled with a vacutainer $(82 \times 10.25 \mathrm{~mm}$, A3274, Becton Dickinson, Vacutainer Systems Europe BP NO37-3841 Meylan Cedex, France) through a puncture of the sclera about $6 \mathrm{~mm}$ posterior to the corneal limbus. One hundred to three hundred microliters of fluid were taken at each sampling. The samples were immediately centrifuged for 10 min at $1800 \times g, 4^{\circ} \mathrm{C}$, to remove cells or other contaminating particles (pigmented pieces of retina), using a Millipore Ultrafree-MC 10.000 NMWL filter unit (Millipore Products Division, Bedford, UK). The clear vitreous humor was transferred into polypropylene tubes and frozen at $-20^{\circ} \mathrm{C}$ until analyzed.

Analysis of hypoxanthine. The hypoxanthine levels in vitreous humor were analyzed by HPLC (12).

Statistics. The Wilcoxon signed rank test was applied for comparing matched variables. The Mann-Whitney $U$ test was applied for comparison of two groups. The Spearman rank correlation test was used for correlation studies. Values are given as medians and ranges. The median, range, and mean \pm $1 \mathrm{SD}$ are given for the duration of the apnea and the hypoxanthine levels in the vitreous humor. 


\section{RESULTS}

\section{Pilot Trials}

B-Endorphin i.c.m. Doses of $0.5(n=1)$ and $1 \mathrm{mg}(n=1)$ of $\beta$-endorphin injected i.c.m. of the piglets induced a decrease in respiratory minute volume, heart rate, and blood pressure during the first $10 \mathrm{~min}$. Within the next $35 \mathrm{~min}$ an irregular respiratory pattern with periods of apnea accompanied by increased blood pressure and a decrease in heart rate followed and lasted 30-50 min before the piglets died (Fig. 1).

A dose of $0.1 \mathrm{mg}$ of $\beta$-endorphin injected i.c.m. of the piglets $(n=19)$ induced similar but less pronounced respiratory and cardiovascular changes. The piglets survived for more than $3 \mathrm{~h}$. During the time of irregular respiratory and cardiovascular patterns induced by $0.1 \mathrm{mg}$ of $\beta$-endorphin i.c.m., the mean respiratory minute volume decreased by $12 \%(p<0.05)$, heart rate decreased by $9 \%(p<0.05)$, and the blood pressure decreased by $8 \%(p<0.01)$ compared with the values before the injection of $\beta$-endorphin. Arterial $\mathrm{PO}_{2}$ and base excess also decreased $(p<0.01)$, but the $\mathrm{PCO}_{2}$ was unchanged. Naloxone, $100 \mu \mathrm{g} / \mathrm{kg}$ i.v. in piglets $(n=6)$ given $5 \mathrm{~min}$ after the start of the $\beta$-endorphin-induced irregular respiratory and cardiovascular patterns, caused an immediate increase of $14 \%$ in the respiratory minute volume $(p<0.05)$, of $11 \%$ in the heart rate $(p<0.05)$, and of $10 \%$ in the blood pressure $(p<0.05)$.

Doses of $0.01 \mathrm{mg}$ of $\beta$-endorphin or water injected i.c.m. in the piglets $(n=3)$ induced no changes in the respiratory minute volume, heart rate, or blood pressure, within $120 \mathrm{~min}$.
Based on these initial studies we decided to inject 0.1 and $0.2 \mathrm{mg}$ of $\beta$-endorphin i.c.m. before we induced the laryngeal chemoreflex.

\section{Main Trials}

Age, weight, blood glucose, Hb, hematocrit, and base excess before the laryngeal chemoreflex-induced apnea. The age, weight, blood glucose, $\mathrm{Hb}$, and hematocrit showed no statistically significant differences between the groups of piglets (Table 1). Only the base excess before the induced apnea was statistical lower in the piglets pretreated with $0.2 \mathrm{mg}$ of $\beta$-endorphin i.c.m. $(p<0.01)$, and with $0.1 \mathrm{mg}$ of $\beta$-endorphin i.c.m. and naloxone i.v. $(p<0.05)$, compared with the piglets pretreated with water i.c.m. (Table 1).

Duration of the laryngeal chemoreflex-induced apnea. The laryngeal chemoreflex response consists of apnea, blood pressure increase, and decrease in heart rate (Fig. 2). Doses of 0.1 $\mathrm{mg}(n=6)$ and $0.2 \mathrm{mg}(n=6)$ of $\beta$-endorphin were injected i.c.m., and the apnea was induced 5 min after the irregular respiratory and cardiovascular patterns had been obtained. The median of the periods of apnea was $29 \mathrm{~s}$ (range $15-70$, mean 40 \pm 13 ) for the piglets pretreated with $0.1 \mathrm{mg}$ of $\beta$-endorphin, and $37 \mathrm{~s}$ (range $15-150$, mean $43 \pm 33$ ) for the piglets pretreated with $0.2 \mathrm{mg}$ of $\beta$-endorphin. The duration of these periods of apnea did not differ significantly from those in the piglets pretreated with water i.c.m. $(n=6)$, which had a median of $24 \mathrm{~s}$ (range 15-55, mean $28 \pm 9$ ) (Fig. 3). However, two of the piglets, pretreated with $\beta$-endorphin, 0.1 and $0.2 \mathrm{mg}$,

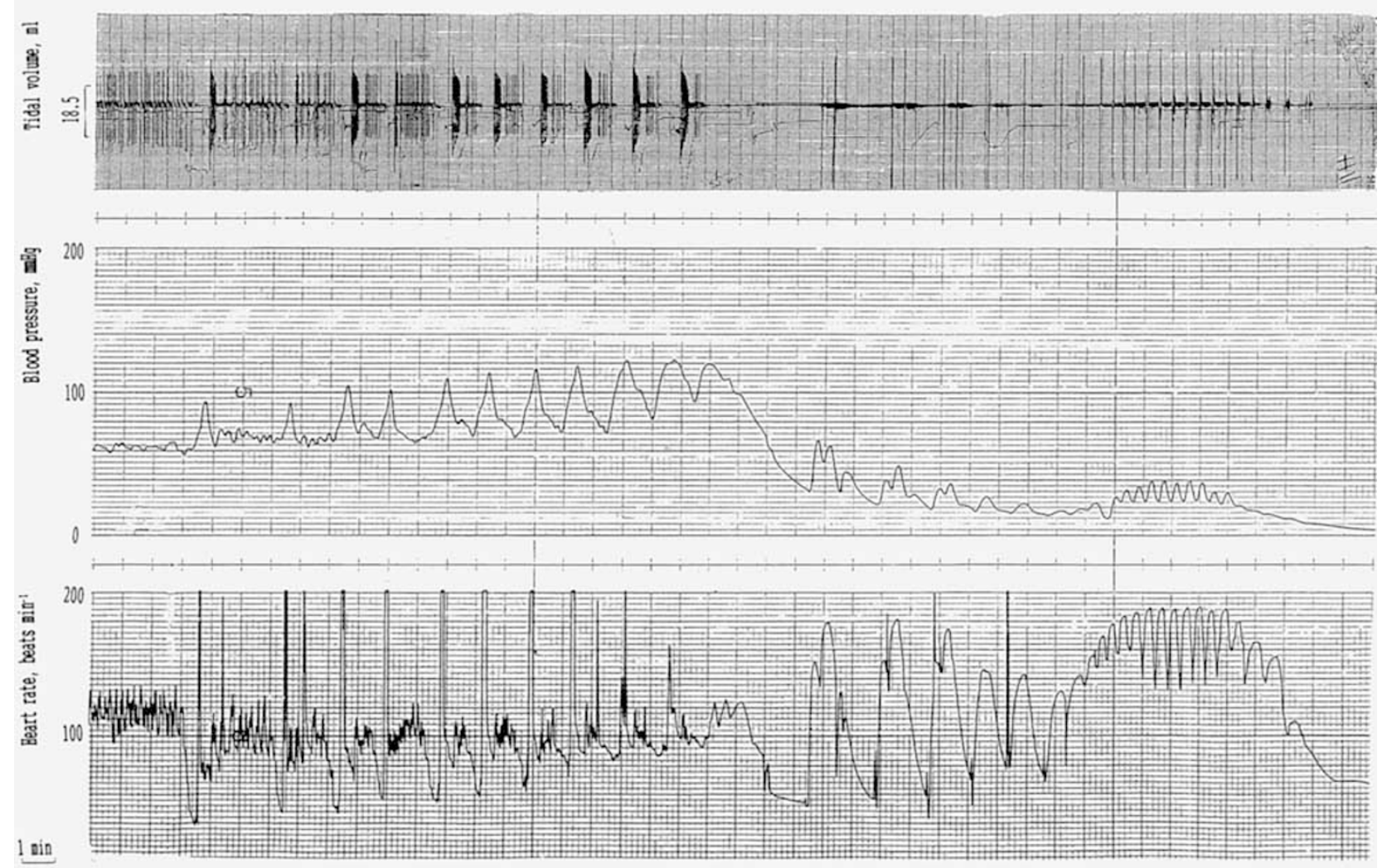

Figure 1. The respiratory and cardiovascular patterns $35-75 \mathrm{~min}$ after the injection of $1 \mathrm{mg}$ of $\beta$-endorphin i.c.m. of a piglet. 
Table 1. Different variables in the piglet groups in which the laryngeal chemoreflex were induced compared with the piglets pretreated with water i.c.m.

\begin{tabular}{|c|c|c|c|c|c|c|}
\hline Variable & Blood glu & $\mathrm{Hgb}$ & Hct & Age/days & Weight/kg & Base excess \\
\hline CONTR & $10(6-12)$ & $7(6-8)$ & $23(18-29)$ & $7(5-9)$ & $2(2-4)$ & $-2(0-6)$ \\
\hline END & $7(7-8)$ & $6(6-7)$ & $25(20-28)$ & $8(7-10)$ & $3(2-4)$ & $-3(-2-7)$ \\
\hline $\mathrm{END} \times 2$ & $7(5-9)$ & $6(4-8)$ & $22(18-25)$ & $6(5-10)$ & $3(1-4)$ & $-6(-5-9) * *$ \\
\hline NAL & $10(7-11)$ & $6(5-7)$ & $21(15-26)$ & $7(5-10)$ & $2(2-4)$ & $-2(6-5)$ \\
\hline END NAL & $7(7-9)$ & $6(6-7)$ & $25(20-28)$ & $8(6-10)$ & $3(2-3)$ & $-6(-4-7)^{*}$ \\
\hline
\end{tabular}

The values are given with median and range. Abbreviations: CONTR $=$ control piglets pretreated with water i.c.m.; END $=0.1 \mathrm{mg}$ of $\beta$-endorphin i.c.m.; END $\times 2=0.2 \mathrm{mg}$ of $\beta$-endorphin i.c.m.; NAL $=$ naloxone i.v.; END NAL $=0.1 \mathrm{mg}$ of $\beta$-endorphin i.c.m. and naloxone i.v.; Blood glu $=$ blood glucose $\mathrm{mmol} / \mathrm{L}$. Base excess mmol/L was measured before the apnoea. ${ }^{* *} p<0.01,{ }^{*} p<0.05$.

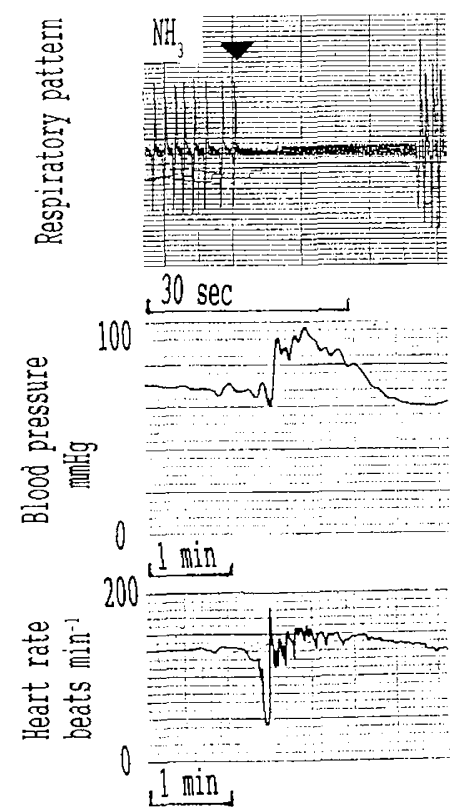

Figure 2. The respiratory and cardiovascular patterns after induction of the laryngeal chemoreflex with $\mathrm{NH}_{3}$-saturated air.

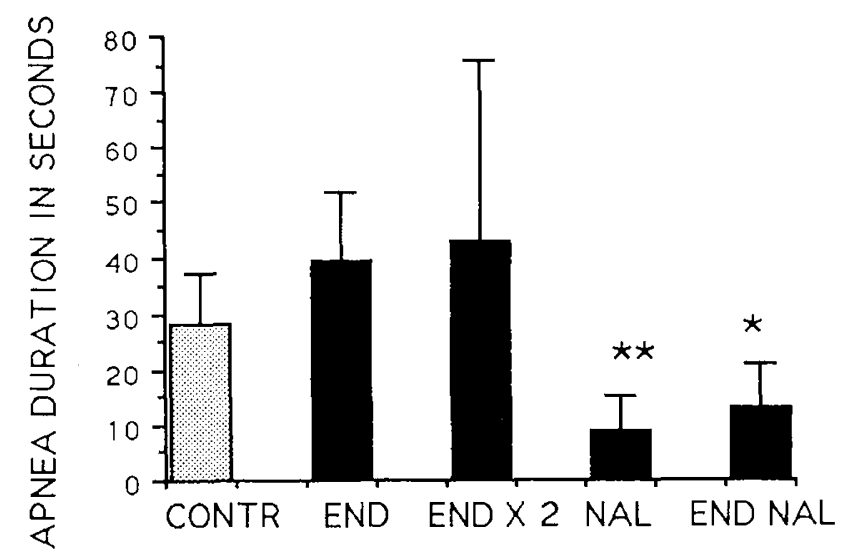

Figure 3. The duration of apnea (mean $\pm S D$ ) during the laryngeal chemoreflex in piglets pretreated with different substances compared with the piglets pretreated with water i.c.m.: $C O N T R=$ controls, water i.c.m. $(n=6) ; E N D=$ $0.1 \mathrm{mg}$ of $\beta$-endorphin i.c.m. $(n=6) ; E N D \times 2=0.2 \mathrm{mg}$ of $\beta$-endorphin i.c.m. $(n=6) ; N A L=$ water i.c.m. and naloxone, $100 \mu \mathrm{g} / \mathrm{kg}$ i.v.; END NAL $=0.1 \mathrm{mg}$ of $\beta$-endorphin i.c.m. and naloxone, $100 \mu \mathrm{g} / \mathrm{kg}$ i.v. ${ }^{* *} p<0.01 ;{ }^{*} p$ $<0.05$ vs CONTR.

respectively, died after the induced apnea. Moreover, when naloxone, $100 \mu \mathrm{g} / \mathrm{kg}$ i.v., was given $5 \mathrm{~min}$ before the induction of apnea $(n=6)$, the median of the duration of the apnea was
$10 \mathrm{~s}$ (range $0-30$, mean $9 \pm 6$ ). These periods of apnea were shorter than those in the piglets pretreated with water i.c.m. ( $n$ $=6)(p<0.01)$ (Fig. 3). The median of the induced apnea in the piglets pretreated with $0.1 \mathrm{mg}$ of $\beta$-endorphin i.c.m., followed by $100 \mu \mathrm{g} / \mathrm{kg}$ naloxone i.v. after the irregular respiratory and cardiovascular patterns had been obtained $(n=6)$, was $11 \mathrm{~s}$ (range $5-29$, mean $13 \pm 8$ ). These periods of apnea were also shorter than those in the piglets pretreated with water i.c.m. $(n=6)(p<0.05)$ (Fig. 3).

Hypoxanthine levels in the vitreous humor after the laryngeal chemoreflex-induced apnea. The median of the hypoxanthine levels in vitreous humor in the piglets which received 0.1 $\mathrm{mg}$ of $\beta$-endorphin i.c.m. $(n=6)$ before the laryngeal chemoreflex-induced apnea, was $21 \mu \mathrm{mol} / \mathrm{L}$ (range $18-27$, mean $22 \pm 6)$. The piglets receiving $100 \mu \mathrm{g} / \mathrm{kg}$ naloxone i.v. $(n=6)$ had a median of $24 \mu \mathrm{mol} / \mathrm{L}$ (range $4-28$, mean $22 \pm 12$ ), and the piglets receiving $0.1 \mathrm{mg}$ of $\beta$-endorphin i.c.m. and naloxone i.v. $(n=6)$ had a median of $27 \mu \mathrm{mol} / \mathrm{L}$ (range $13-29$, mean $23 \pm 12$ ). The hypoxanthine levels in these piglet groups were not statistically significant different from those pretreated with water i.c.m. $(n=6)$, which had a median of $28 \mu \mathrm{mol} / \mathrm{L}$ (range 15-43, mean $27 \pm 10$ ) (Fig. 4). The piglets which received $0.2 \mathrm{mg}$ of $\beta$-endorphin i.c.m. $(n=6)$ before the laryngeal chemoreflex-induced apnea had higher hypoxanthine levels in the vitreous humor, with a median of $43 \mu \mathrm{mol} / \mathrm{L}$

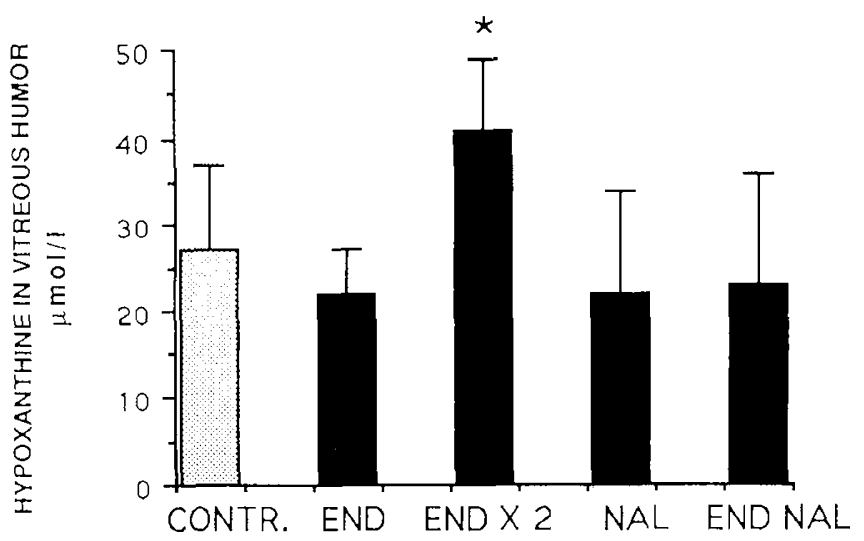

Figure 4. Postmortem levels of hypoxanthine in vitreous humor (mean \pm $\mathrm{SD}$ ) in piglets pretreated with different substances before the induced laryngeal chemoreflex compared with the piglets pretreated with water i.c.m.: CONTR = controls, water i.c.m. $(n=6) ; E N D=0.1 \mathrm{mg}$ of $\beta$-endorphin i.c.m. $(n=6)$; $E N D \times 2=0.2 \mathrm{mg}$ of $\beta$-endorphin i.c.m. $(n=6) ; N A L=$ water i.c.m. and naloxone, $100 \mu \mathrm{g} / \mathrm{kg}$ i.v.; $E N D N A L=0.1 \mathrm{mg}$ of $\beta$-endorphin i.c.m. and naloxone, $100 \mu \mathrm{g} / \mathrm{kg}$ i.v.; * $p<0.05$ vs CONTR. 
(range 29-47, mean $41 \pm 8$ ), than the piglets pretreated with water i.c.m. $(n=6)(p<0.05)$ (Fig. 4).

Blood gases and the respiratory minute volume before and after the laryngeal chemoreflex-induced apnea. In the piglets pretreated with water i.c.m. $(n=13)$ only, the $\mathrm{PO}_{2}$ was decreased from a median of $9.5 \mathrm{kPa}$ before the laryngeal chemoreflex-induced apnea to $8.5 \mathrm{kPa} 5$ min after the periods of induced apnea $(p<0.05)$. The $\mathrm{PCO}_{2}$, base excess, and minute volume were unchanged.

The duration of the laryngeal chemoreflex-induced apnea related to the increase in blood pressure and the decrease in heart rate. In the piglets pretreated with water i.c.m. $(n=13)$, the duration of the apnea was correlated with the increase in blood pressure, $r=0.87(p<0.01)$. The duration of the apnea was not related to the drop in heart rate, $r=0.4(p=0.19)$.

Increase in blood pressure related to the decrease in heart rate during the laryngeal chemoreflex. During the apnea, the increase in blood pressure was not related to the decrease in heart rate during the induced apnea in the piglets $(n=13), r=$ $0.4(p=0.13)$.

\section{DISCUSSION}

The main finding in this study was that naloxone reduced the duration of laryngeal chemoreflex-induced apnea. This reflex consists of prolonged expiration, an increase in blood pressure, and a decreased heart rate. Furthermore, $0.1-1 \mathrm{mg}$ of $\beta$-endorphin i.c.m. caused a decrease in respiratory minute volume, heart rate, and blood pressure within $15 \mathrm{~min}$. Within $45 \mathrm{~min}$ respiratory pauses developed with accompanying blood pressure increases and decreases in the heart rate (Fig. 1), similar to the respiratory and cardiovascular pattern of the induced laryngeal chemoreflex (Fig. 2).

Interestingly, $\beta$-endorphin has been found to increase the expiratory phase of the tidal volume (13) and naloxone to shorten the Heuring Breuer reflex (14).

The respiratory pattern in piglets induced by $\beta$-endorphin seems to contain a mechanism different from that of adult dogs (13). The respiratory pattern may be due to activation of $\mu$-receptors situated at different anatomical sites after diffusion of $\beta$-endorphin. Superficial activation of receptors on the dorsal pons induced a decreased tidal volume and decreased sensitivity to $\mathrm{CO}_{2}$. Activation of the superficial receptors of the ventral medulla induced a decreased tidal volume, decreased respiratory rate, and decreased sensitivity to $\mathrm{CO}_{2}$, and activation of receptors in the ambiguous nucleus induced a decrease in respiratory rate (4).

In adult rats activation of $\mu$-receptors by nanomolar dermorphin i.c.m. induced a heart and respiratory rate decrease and blood pressure increase $(15,16)$. Dermorphin i.c.m. has been found to also induce catecholamine release in plasma (16). A significant correlation has been found between the mean arterial blood pressure increase and the plasma levels of norepinephrine after dermorphin administration i.c.m. (16). Catecholamine also induced a decreased blood flow to the renal and intestinal arteries (16).

When comparing these findings with studies of the laryngeal chemoreflex, it is interesting that the systemic blood pressure increase is lower after hyperoxia (decreased stimulation of arterial chemoreceptors) and after $\alpha$-adrenergic blockade during the laryngeal chemoreflex (17). During the laryngeal chemoreffex, blood from the kidneys, intestines, and lower/upper extremities is redistributed to the brain and bronchioles. This redistribution of blood is also counteracted by $\alpha$-adrenergic blockade (17). Because $\mu$-agonists release catecholamines in plasma, the blood pressure increase and the blood flow redistribution during the laryngeal chemoreflex may be partly due to release of norepinephrine caused by a $\mu$-agonist.

The decrease in heart rate during the laryngeal chemoreflex is significantly reduced after hyperoxia and after a parasympathetic blockade (17). The blood pressure increase and heart rate decrease during laryngeal chemoreflex are also influenced by stimuli from the lung-inflating receptors (17).

Furthermore, neither hyperoxia, nor $\alpha$ - or $\beta$-adrenergic blockades influence the duration of the apnea during this reflex (17). Atropine, however, does decrease the duration (18). Because $\beta$-endorphin levels in the CSF after the laryngeal chemoreflex-induced apnea correlated significantly with the duration of the apnea (9), and because naloxone decreases respiratory depression during this reflex, the laryngeal chemoreflex-induced apnea in piglets may partly be due to stimulation of $\mu$-receptors. Also the respiratory and cardiovascular patterns seen after injection of $0.1-1-\mathrm{mg}$ doses of $\beta$-endorphin i.c.m., which are similar to those in laryngeal chemoreflex, may indicate an activation of $\mu$-receptors.

Interestingly, vagotomy sustains the vasomotor effect but eliminates the respiratory and heart rate depression to $\beta$-endorphin injected i.c.m. (13). Moreover, 0.1 and $0.2 \mathrm{mg}$ of $\beta$-endorphin i.c.m. did not significantly prolong the duration of the apnea during the laryngeal chemoreflex. This may be because the apnea stimulus induced enough $\beta$-endorphin release to saturate the $\mu$-receptors (9), or because $\beta$-endorphin did not reach the nuclei involved in the reflex. A third possibility is that higher doses of opiates would have prolonged the apnea. It is concluded that $\beta$-endorphin is involved in the induction of the apnea during laryngeal chemoreflex, possibly by activating $\mu$-receptors.

Acknowledgments. The authors thank Runar Almaas, Roger $\emptyset$ degaard, and Ansgar Aasen for their assistance.

\section{REFERENCES}

1. Orolowski JP 1986 Cerebrospinal fluid endorphins and infant apnoea syndrome. Pediatrics 78:233-237

2. Myer EC, Morris DL, Brase DA, Dewey WL, Zimmerman AW 1990 Naltrexone therapy of apnoea in children with elevated cerebrospinal fluid $\beta$-endorphin. Ann Neurol 27:75-80

3. Brandt NJ, Terenius L, Jacobsen BB, Klinken L, Nordius $\AA$, Brandt S, Blegvad $K$, Yssing M 1980 Hyper-endorphin syndrome in a child with necrotizing encephalomyelopathy. N Engl J Med 914:916

4. Shook JE, Watkins WD, Camporesi EM 1990 Differential roles of opioid receptors in respiration, respiratory disease, and opiate-induced respiratory depression. Am Rev Respir Dis 142:895-909

5. Serre MA, Monin P, Feillet F, Dousset B, Vidailhet M 1994 Gastroesophagal reflux (GER) and ALTE in babies: Role of $\beta$-endorphins? Pediatr Res 35:268

6. Bayert C, Monin P, Dousset B, Marchal F 1994 Decreased plasma $\beta$-endorphins levels (BE) after treatment of gastro-oesophageal reflux (GER) in babies admitted for acute life-threatening episodes (ALTE). Pediatr Res 36:61A(abstr)

7. Wennergren G, Bjure J, Hertzberg T, Lagercrantz H, Milerad J 1993 Laryngeal reflex. Acta Paediatr 82:53-56 
8. Jimenez-Vargas J, Carreira-Monteiro E 1986 Opioides endogenos en la inhibicon respiratoria por estimulacion laringea. Rev Esp Fisiol 42:147-152

9. Storm H, Stoltenberg L, Saugstad OD, Rognum TO, Reichelt KL, $\beta$-Endorphin levels in CSF after a laryngeal chemoreflex induced apnoea correlate with the duration of the apnoca. J Perinatol Med (in press)

10. Freedman A, Scardella AT, Edelman NH, Santiago TV 1988 Hypoxia does not increase CSF or plasma $\beta$-endorphin activity. J Appl Physiol 64:966-971

11. Moss IR, Inman JG 1989 Proopiomelanocortin opioid in brain, CSF, and plasma of piglets during hypoxia. $J$ Appl Physiol 66:2280-2286

12. Saugstad OD, Rognum TO 1988 High postmortem vitreous hypoxanthine in newborns with the respiratory distress syndrome (RDS) Pediatrics 81:395-398

13. Moss IR, Scarpelli EM $1981 \beta$-Endorphin central depression of respiration and circulation. J Appl Physiol 50:1011-1016
14. Chow CM, Read DJC 1984 Effects of naloxone on the Hering-Breuer apnoea in sleeping kittens. J Appl Physiol 56:51278-51282

15. Paakkari P, Paakkari I, Siren AL, Feuerstein G 1990 respiratory and locomotor stimulation by low doses of dermorphin, a $\mu 1$ receptor-mediated effect. J Pharmacol Exp Ther 252:235-240

16. Siren AL, Paakkari P, Goldstein DS, Feuerstein G 1989 Mechanisms of central hemodynamic and sympathetic regulation by $\mu$ opioid receptors: effects of dermorphin in the conscious rat. J Pharmacol Exp Ther 248:596-604

17. Grogaard J, Lindstrom DP, Stahlman MT, Marchal F, Sundell H 1982 The cardiovascular response to laryngeal water administration in young lambs. J Dev Physiol $4: 353-370$

18. Rimell F, Goding GS, Johnson K 1993 Cholinergic agents in the laryngeal chemoreflex model of sudden infant death syndrome. Laryngoscope 103:623-630 